\title{
A CONSTRUÇÃO DA REDE DE EDUCAÇÃO EM DIREITOS HUMANOS: A EXPERIÊNCIA DA UFPA
}

\section{The construction of the Network for Education in Human Rights: the experience of UFPA}

\section{La construcción de la Red de Educación en Derechos Humanos: la experiencia de la UFPA}

\author{
Alberto Damasceno ${ }^{1}$ \\ Émina Márcia Nery dos Santos ${ }^{2}$ \\ Ney Cristina Monteiro de Oliveira ${ }^{3}$ \\ Marcos Vinícius Lobo ${ }^{4}$ \\ Pedro Henrique Queiróz $z^{5}$
}

\begin{abstract}
RESUMO
Este trabalho apresenta a experiência da Universidade Federal do Pará no Projeto REDE DE EDUCAÇÃO EM DIREITOS HUMANOS (REDH), cujo objetivo é desenvolver ações para a implementação de uma cultura de Direitos Humanos nos sistemas de ensino por meio da capacitação e desenvolvimento de atividades em educação em direitos humanos para e com a comunidade escolar (educadores, técnicos e gestores) da rede de educação básica, lideranças, profissionais das cinco áreas do Plano Nacional de Educação em Direitos Humanos e profissionais da área de saúde. O curso proposto pela UFPA é realizado na cidade de Belém (PA) e em mais três municípios da Ilha do Marajó (Breves, Gurupá e Soure).

Palauras-chave: Educação; Direitos Humanos e Extensão Universitária.
\end{abstract}

\begin{abstract}
This study presents the experience of Universidade Federal do Pará in the project NETWORK FOR EDUCATION IN HUMAN RIGHTS, whose objective is to develop actions towards a culture of Human Rights in education systems through training and development activities in education for human rights aiming the school community (teachers, technicians and managers) of the network of basic education, leaders, professionals in five areas of the National Plan for Human Rights Education and health professionals in the area. The course offered by UFPA is held in the city of Belém (PA) and in three more districts of the Marajó island (Breves, Gurupá and Soure).

Keywords: Education; Human rights and Science outreach.
\end{abstract}

\footnotetext{
1 Doutor em Educação (PUC/SP), professor associado da Universidade Federal do Pará lotado no Instituto de Ciências da Educação, pesquisador do GESTAMAZON . Atualmente é titular da Diretoria de Assistência e Integração Estudantil da Pró-Reitoria de Extensão. 2 Doutora em Ciências Ambientais (NAEA/UFPA), professora do Instituto de Ciências da Educação da UFPA, pesquisadora do GESTAMAZON, atualmente é Diretora de Programas e Projetos da Pró Reitora de Extensão.

3 Doutora em Educação (PUC/SP), professora da Universidade Federal do Pará lotada no Instituto de Ciências da Educação, pesquisadora do GESTAMAZON . Atualmente é Pró Reitora de Extensão da UFPA, presidente do Fórum de Pró-Reitores de Extensão das Universidades Públicas Brasileiras - FORPROEX.

4 Acadêmico do Curso de Odontologia da UFPA, membro do Programa MULTICAMPISOCIAL.

5 Acadêmico do Curso de Odontologia da UFPA, membro do Programa MULTICAMPISOCIAL, bolsista do REDH/UFPA.
} 


\section{RESUMEN}

Esto trabajo presenta la experiencia de la Universidade Federal do Pará en el Proyecto de Red de Educación en Derechos Humanos (REDH), cuyo objetivo es desarrollar acciones hacia una cultura de los derechos humanos en los sistemas educativos mediante la capacitación y las actividades de desarrollo en la educación de los derechos humanos y la comunidad escolar (profesores, técnicos y directivos) de la red de la educación básica, los dirigentes, los profesionales en cinco áreas del Plan Nacional para la Educación en Derechos Humanos y de los profesionales de la salud. El curso es ofrecido por UFPA, celebrado en la ciudad de Belém (Pará) y en otros tres distritos de la isla del Marajó (Breves, Gurupá y Soure) Palabras-clave: Educación; Derechos Humanos y Extensión Universitaria.

A ressignificação da extensão universitária e seu papel na construção de estratégias de controle social

As ressignificações das relações entre estado, sociedade civil e mercado presentes na dinâmica de organização político-administrativa do território nacional, geraram a exigência de novos posicionamentos por parte de suas instituições com a finalidade de incluir e dar visibilidade a grupos sociais tradicionalmente excluídos do cenário da vida pública brasileira.

$\mathrm{Na}$ lógica de institucionalização de um novo contrato social que agregue novos protagonistas e novas demandas sociais, as Universidades públicas assumiram como missão a organização de redes dialogais com setores da sociedade na perspectiva da produção de novos saberes capazes de qualificar a vida das populações da região amazônica.

Importante nesse contexto, a atividade da extensão universitária adquiriu maior significado, pois é potencialmente capaz de maximizar as condições para a participação da Universidade Pública na elaboração das políticas de Estado voltadas para a maioria da população, bem como para sua constituição em organismo legítimo no controle social da implantação de tais políticas.

Altera-se, deste modo, a dimensão e a substância das ações extensionistas universitárias para além de políticas assistencialistas, elemento que estruturou a existência de tal atividade como tripé da missão institucional da universidade, qualificando-a como processo acadêmico definido e efetivado em função das exigências da realidade, indispensável na formação do aluno, na qualificação do professor e no intercâmbio com a sociedade.

O entendimento do salto de qualidade exercido por estas atividades carece de argumentação teórico-conceitual para que não transpareça a sensação de naturalização das atividades humanas a partir de determinismos sem substância e, desta forma, possa ser resgatada a importância histórica da extensão na construção de uma universidade sustentável.

Os primeiros documentos que tratam da questão de extensão nas universidades brasileiras datam do início dos anos 30 do século passado. Na "Exposição de Motivos sobre a Reforma das Universidades Brasileiras", de abril de 1931, a "extensão universitária se destina a dilatar os benefícios da atmosfera universitária aqueles que não se encontram diretamente associados à vida da universidade". Em outro documento, do mesmo ano, os cursos de extensão universitária eram "destinados a propagar, em benefício coletivo, a atividade técnica e científica dos institutos universitários".

A ambiguidade da expressão "benefício coletivo" permite questionar o compromisso social da política de extensão das universidades brasileiras à época. Permite, também, concluir que a diretriz de um assistencialismo difuso, mas direcionado concreta e ideologicamente, nunca esteve tão bem explicitada como no Estatuto das Universidades Brasileiras datado de 1931.

O golpe de 1937 e a ditadura Varguista estenderam suas marcas até o final dos anos 60 . Durante quarenta anos os documentos trataram

Extensão em Foco, Curitiba, n. 6, p. 125-132, jul./dez. 2010. Editora UFPR 
a extensão universitária de forma secundária, acessória ou simplesmente não trataram.

A extensão, definida como um dos objetivos-fim da Universidade Brasileira e institucionalizada de forma sistemática e oficial no interior da Academia, foi produto da Reforma Universitária de $1968^{6}$, marco normativo que estabelece que "as universidades $e$ as instituições de ensino superior estenderão à comunidade, sob forma de cursos e serviços especiais, as atividades de ensino e os resultados da pesquisa que lhe são inerentes".

Anteriormente à Reforma, as experiências que poderiam caber dentro desse espectro de preocupação representavam iniciativas isoladas, geralmente assistemáticas, quando não episódicas, limitadas por um contexto histórico onde a Universidade, quando muito, era vista como uma boa escola de terceiro grau, formadora de quadros profissionais educados dentro de padrões culturais e técnicos importados dos centros mais dinâmicos do mundo capitalista ocidental, particularmente os Estados Unidos, França e Inglaterra.

Entretanto, as ambiguidades ou desatenções das políticas públicas para as atividades de extensão não lograram impedir que algumas experiências socialmente compromissadas ${ }^{7}$ existissem à sombra ou à margem das universidades brasileiras ao longo desses anos.

Essas divergências quanto ao papel que a universidade deveria cumprir no interior de uma sociedade periférica e dependente acirraram-se com o golpe de 64 pois, a partir de então, as atividades de extensão foram canceladas tal como eram $e$ assimiladas e retrabalhadas pelas reformas introduzidas em 1968, quando passa a predominar no espaço universitário a concepção de extensão enquanto "prestação de serviços",

6 Por meio do artigo 20 da Lei $n^{\circ} 5.540$, de 28 de novembro de 1968.

7 Algumas vivências não podem passar desapercebidas, dentre elas: O Movimento da Cultura Popular, os CPC's (Centro de Cultura Popular, ativados pela UNE), a campanha "De Pé no Chão Também se Aprende a Ler", o Movimento de Educação de Base (MEB), o Serviço de Extensão Rural da UFPE, a Universidade Volante (da UFPR) e, até um certo momento, o CRUTAC - Centro Rural Universitário de Treinamento e Ação Comunitária, são experiências que representavam vertentes ideológicas diferenciadas dentro da academia. a exemplo de instituições norte-americanas, à reboque dos Acordos MEC-USAID ${ }^{8}$.

No que tange à UFPA, a introdução do seu Plano Diretor de Extensão para 1976-1979 revela não só a percepção dessas diferenças, como sugere caminhos para a sua "correção". O assistencialismo e a descontinuidade, enquanto características das atividades extensionistas das universidades brasileira se reproduz na nossa universidade desde sua fundação, em 57 , até a criação do CRUTAC $^{9}$ em 1972. Tendo como origem em sua maioria, os Departamentos dos Centros de Exatas e de Saúde e como destino a população da cidade de Belém. A extensão na UFPA variava das prestações de serviços técnicos a entidades públicas e privadas até $\mathrm{o}$ atendimento odontológico às comunidades da capital do estado. Em menor escala ocorreram atividades oriundas das áreas de ciências humanas e socioeconômicas e na área cultural.

Com o advento da reforma universitária e a criação da Subreitoria de Assuntos de Extensão e Natureza Estudantil, a UFPA deu início a uma série de medidas de caráter administrativo com o objetivo de oferecer aos agentes de extensão condições para um trabalho mais integrado, interdisciplinar e homogêneo, do ponto de vista institucional.

A partir dos anos 80 o foco das atividades de extensão se deslocou para o atendimento de propostas mais "regionais", voltadas para as necessidades que emergissem da própria comunidade. Mesmo após a realização do I Seminário e Extensão da Amazônia - articulado e coordenado pela UFPA - onde se detectou uma nova retórica extensionista, foram poucas as propostas estruturadas de forma participativa. Entretanto uma das maiores demonstrações do poder transformador da

\footnotetext{
8 Foram acordos produzidos nos anos 1960 do século passado, entre o Ministério da Educação do Brasil (MEC) e a United States Agency for International Development (USAID). Tais acordos visavam garantir assistência técnica e cooperação financeira à educação brasileira em seus diferentes níveis. $\mathrm{O}$ período que foi de junho de 1964 e janeiro de 1968 foi o de maior intensidade nos acordos, sendo firmados nada menos que doze deles.
} 
extensão universitária na UFPA foi dada a partir da implantação dos campi no interior do estado, fator estruturante no dimensionamento multicampi da universidade ${ }^{10}$, sobretudo com o estabelecimento de duas unidades na ilha do Marajón ${ }^{11}$.

Naquela região se encontram os piores índices de desenvolvimento humano do País e do Estado de modo que seus municípios apresentam baixíssimo índice de qualidade de vida e, ainda que tenham apresentado algum crescimento na década passada, a situação global ainda é de profundas necessidades, corroborando a tese de que a ilha ainda é uma fronteira social a ser conquistada por meio de ações de desenvolvimento humano e cidadania.

\begin{tabular}{|c|c|c|c|c|c|c|c|c|}
\hline & $\begin{array}{c}\text { IDH } \\
(1)\end{array}$ & $\begin{array}{c}\text { IDEB* } \\
(2)\end{array}$ & $\begin{array}{c}\text { IDI } \\
(3)\end{array}$ & $\begin{array}{c}\text { Taxa de } \\
\text { Escolarização } \\
\text { líquida EF } \\
(4)\end{array}$ & $\begin{array}{c}\text { Taxa de } \\
\text { Escolarização } \\
\text { líquida EM } \\
(4)\end{array}$ & $\begin{array}{c}\text { Taxa de } \\
\text { analfabetismo (10 } \\
\text { a 15 anos) } \\
(5)\end{array}$ & $\begin{array}{c}\text { Taxa de } \\
\text { analfabetismo (15 } \\
\text { ou mais) } \\
(5)\end{array}$ & $\begin{array}{c}\text { População } \\
(6)\end{array}$ \\
\hline Breves & 0,630 & 2,5 & 0,360 & 77,0 & 5,1 & 35,80 & 35,80 & 94.458 \\
\hline Gurupá & 0,630 & 2,1 & 0,340 & 76,6 & 1,8 & 31,90 & 35,00 & 24.384 \\
\hline Soure & 0,723 & 2,6 & 0,690 & 22.244 & 83,5 & 11,60 & 13,10 \\
\hline
\end{tabular}

do Estado nas opções culturais e condições de moradia muito pobres em termos materiais.

O problema do abuso e exploração sexual de crianças e adolescentes, que já era grave, chegou a níveis alarmantes, pois agora se trata da comercialização do corpo de meninas a partir de onze anos de idade com aval das próprias famílias, posto que esta é a única forma de verem garantidas a sua sobrevivência. As balsas e navios que transportam mercadorias ficam parados em pontos combinados, esperando as barcaças atracarem $e$ as meninas passarem para elas.

Tais denúncias são oriundas de diversas fontes, feitas por inúmeros setores da sociedade, desde a Igreja Católica até o Ministério Público do Estado. Em síntese, as crianças não vão à

FONTE: (1) ÍNDICE DE DESENVOLVIMENTO HUMANO - PNUD - 2000; (2) MEC 2007; 3) ÍNDICE DE DESENVOLVIMENTO DA INFÂNCIA - UNICEF - 2004; (5) IBGE - CENSO DEMOGRÁFICO DE 2000 (6) IBGE - CONTAGEM 2007; *IDEB ANOS INICIAIS

Uma análise ainda que sucinta dos indicadores sociais dos municípios da ilha permite-nos concluir pela existência de grande concentração da renda, elevada mortalidade infantil, desnutrição, malária e óbitos por doenças parasitárias. Acrescente-se a isso uma grande carência por obras de infra-estrutura para saneamento ambiental, tratamento mais abrangente dos serviços de saúde pública e a necessidade de mais escolaridade, o que se representa por elevada taxa de analfabetismo, pouca presença

10 Foi a partir de ações de assistência à saúde da população e de ações de ensino - que remontam mais freqüentemente à década de 1950 - que a instituição percebeu a necessidade de se estabelecer formalmente em outras cidades do Pará já nos anos de 1980. Antes de serem concebidas no conjunto de uma política de extensão, as atividades sofreram o impacto das variações no conceito de extensão universitária ocorridas em todo o país. Ganharam marcos regulatórios e atualmente são estimuladas a estarem cada vez mais aliadas à pesquisa $e$ ao ensino $e$ a provocarem novamente mudanças nas instâncias acadêmicas.

11 Campi Universitários de Breves e Soure.

escola porque a trocam pela necessidade de sobrevivência e se prostituem com o aval dos pais. Por isso este projeto tem características preponderantemente educativo-culturais, cujos resultados dependem de outros vetores político-sociais e cujo prazo não é curto. Todavia, teremos possibilidade de êxito na medida em que contarmos com uma rede de proteção que precisa ser construída $e$ fortalecida permanentemente, sobretudo em se tratando das áreas da educação, saúde e assistência social no âmbito do município.

Confrontada com seu inestimável papel social e sua missão institucional, a Universidade Federal do Pará, em conjunto com as Secretarias Municipais de Educação, de Saúde e de Assistência Social, possui um papel decisivo na efetividade das políticas sociais naquela região, em particular na 
formação inicial e continuada de agentes multiplicadores dos Direitos Humanos.

\section{Construindo a rede nacional de educação} em direitos humanos

A Temática dos Direitos Humanos e Justiça $^{12}$, que é constituinte do Plano Nacional de Extensão desde 2001, fato que contribuiu com a sistematização de diversas experiências em direitos humanos nas universidades brasileiras.

Dentre estas experiências, destacamos as ações do projeto Educação em Direitos Humanos, concebido pela Universidade Federal da Paraíba- UFPB $^{13}$ e executado por meio da sua Pró-Reitoria de Extensão e Assuntos Comunitários (Núcleo de Cidadania e Direitos Humanos). Sua estrutura de financiamento institucional se originou na Secretaria de Educação Continuada, Alfabetização e Diversidade - SECAD, do Ministério da Educação e no âmbito da parceria executiva contou com a presença do Fórum de Pró-Reitores de Extensão das Universidades Públicas Brasileiras - FORPROEX.

As ações do Projeto tiveram início em agosto de 2007, tendo como parceiros os seguintes estados: Acre, Alagoas, Amapá, Amazonas, Bahia, Distrito Federal, Espírito Santo, Goiás, Mato Grosso do Sul, Minas Gerais, Pará, Paraná, Rio de Janeiro, Rio Grande do Sul e Sergipe, que por meio de suas Universidades Públicas executaram as ações do Projeto. As IFES envolvidas são: UNIFAP, UFAC, UFAM, UFPA, UFAL, UFS, UFBA, UFES, UFRJ,UFVJM, UNB, UFG, UFMS, UFPR e FURG;

Destacam-se como objetivos específicos da Rede ações voltadas para a concepção, planejamento, execução, monitoramento e avaliação, sistematização e publicização de experiências de formação de agentes direta ou indiretamente en-

12 Além desta, outras seis temáticas compõem o PNE, que são: Educação, Saúde, Meio Ambiente, Tecnologia e Produção, Cultura e Comunicação.

13 Maiores informações podem ser encontradas no site: www. redhbrasil.net/oprojeto restrito.php

Extensão em Foco, Curitiba, n. 6, p. 125-132, jul./dez. 2010. Editora UFPR volvidos com a inserção da temática dos direitos humanos em ações educativas das unidades escolares dos estados referidos.

Metodologicamente as ações da REDH são executadas em um curso de 132 horas/aula (onde 60 são presenciais, 24 são práticas e 40 referem-se à orientação à distância) dispostas em 4 módulos assim dispostos:

1. Fundamentos históricos e ético-filosóficos da Educação em Direitos Humanos;

2. Fundamentos Políticos e Jurídicos da Educação em Direitos Humanos;

3. Fundamentos Culturais da Educação em Direitos Humanos;

4. Fundamentos Educacionais da Educação em Direitos Humanos.

A parceria com as universidades nos 15 estados envolvidos, a partir do intercâmbio de professores envolvidos na temática, permite que, em um primeiro momento os módulos aconteçam concomitantemente nas 15 capitais-sede e sejam replicados, em um momento posterior, de acordo com o Plano de Trabalho proposto por cada universidade, em municípios circunvizinhos, eleitos a partir dos seguintes critérios: baixos índices no IDEB, presença e citação no mapa nacional de violência, ser sede de outros projetos federais que façam referência aos Direitos Humanos, como o "Escola que Protege", por exemplo, dentre outros.

Como resultados obtidos parcialmente pelo projeto podemos elencar o acervo bibliográfico de autoria de vários professores, que em parceria com a SECAD/MEC idealizaram e levaram à produção do livro "Direitos Humanos:capacitação de educadores", composto por dois volumes, que serviu de subsídio para os cursistas durante a capacitação, além de um CD-ROM contendo as mesas-redondas gravadas e apresentadas durante os módulos e com vídeos utilizados como instrumentos metodológicos na capacitação; $e$, por fim, em processo de finalização, uma coletânea de textos, com um texto para 
cada IFES com o relato de experiência de cada projeto, contendo dados qualitativos e quantitativos de todos os Estados.

\section{A experiência no Pará}

No Pará, os módulos de capacitação da $\mathrm{REDH}$, além de ocorrerem na capital, foram realizados nos municípios de Breves, Gurupá e Soure, sediados na ilha do Marajó, em função de corresponderem aos critérios de escolha definidos pelas instituições parceiras do Programa, isto somado à existência de contatos consolidados anteriormente por intermédio de professores da UFPA que já possuíam trabalhos de pesquisa e extensão na região, fator que facilitou a relação mais estreita com suas respectivas Secretarias de Educação, de Saúde e de Assistência Social. Estas condições os avalizaram como potenciais parceiros e loci de irradiação de ações de planejamento, gestão e execução de políticas sociais relacionadas às diretrizes do programa, o que contribuiu para a premissa de sustentabilidade e continuidade das proposições implementadas.

Dividida em 4 (quatro) módulos o processo de capacitação aconteceu primeiramente em Belém, onde o módulo Fundamentos Histórico-Filosóficos dos Direitos Humanos foi realizado no período de $1^{\circ}$ a 2 de agosto de 2008 , quando se discutiu a construção de uma rede nacional de educadores em Direitos Humanos, assim como a inserção do estado do Pará como parte da mesma.

A "Capacitação de Educadores da Rede Básica de Ensino em Educação em Direitos Humanos" tem como objeto a promoção de mudanças no sistema educacional de ensino no sentido de implementar uma cultura de Direitos Humanos nas escolas por meio da capacitação de educadores, técnicos e gestores da rede básica de educação, lideranças comunitárias, profissionais das cinco áreas (Educação básica, superior, nãoformal, dos profissionais dos sistemas de justiça e segurança e educação e mídia) do Plano Nacional de Educação em Direitos Humanos, junto a quinze estados da federação.

Um aspecto de grande relevância foi a participação efetiva de diversos representantes das esferas governamentais estaduais e municipais, Organizações Não-Governamentais e membros e entidades do Movimento Social, além da presença de Professores da Rede Básica de Ensino, público-alvo desse projeto.

\section{DISTRIBUIÇÃO DOS CURSISTAS POR GÊNERO}

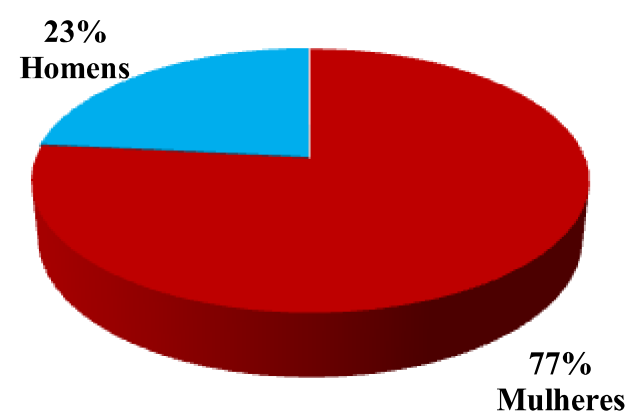

\section{DISTRIBUIÇÃO DOS CURSISTAS POR COR / ETNIA}

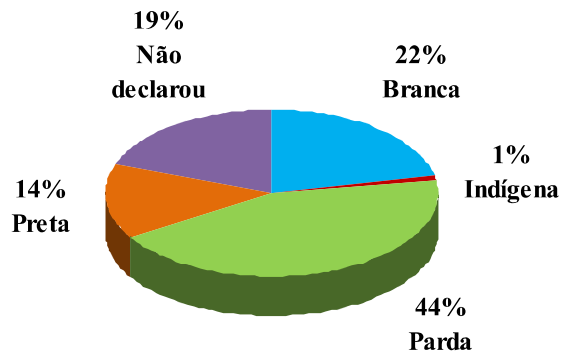

DISTRIBUIÇÃO DOS CURSISTAS POR FORMAÇÃO SUPERIOR

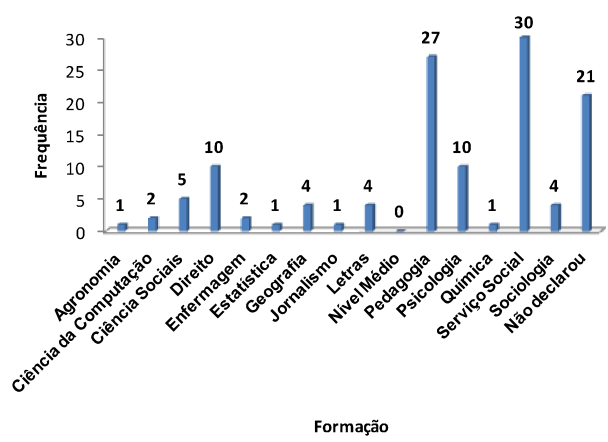

Extensão em Foco, Curitiba, n. 6, p. 125-132, jul./dez. 2010. Editora UFPR 
DISTRIBUIÇÃO DOS CURSISTAS POR ESCOLARIDADE

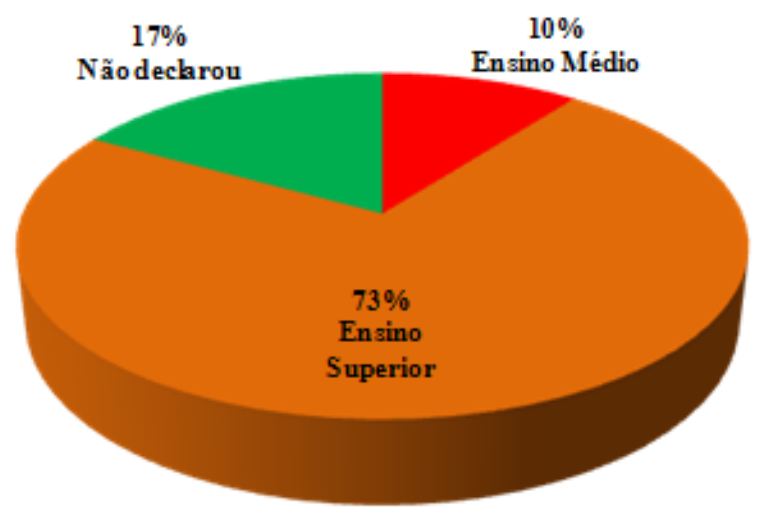

DISTRIBUIÇÃO DOS CURSISTAS POR FAIXA ETÁRIA

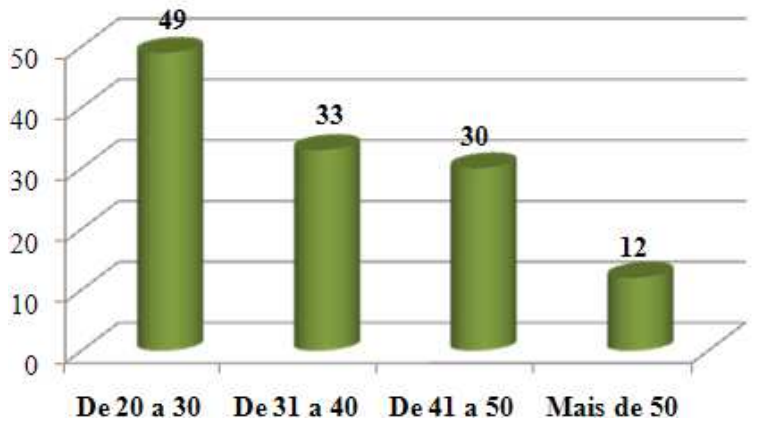

Nos municípios de Breves, Gurupá e Soure, localizados na Ilha do Marajó, o projeto ainda se encontra em fase de conclusão, com previsão de término para o $1^{\circ}$ semestre de 2009, porém está sendo realizado de modo semelhante à capital, embora adaptado às realidades locais. Uma dificuldade considerável na realização dos módulos no interior da Amazônia, consiste nas dinâmicas de mobilização dos cursistas, preocupação maior da coordenação no Estado.

Ao final dos módulos tanto na capital como nos municípios da llha do Marajó, será criado um Plano de Ação em Educação em $e$ para Direitos Humanos, onde serão planejadas ações com a comunidade escolar, construindo metas que visam levar informações básicas relativas ao objeto do programa, capacitando os docentes para a elaboração de materiais didáticos a respeito dos Direitos Humanos e, tendo por objetivo final, informar a comunidade do entorno escolar a respeito do assunto, fazendo valer os direitos fundamentais previstos na constituição brasileira.

Conclusões: perspectivas de continuidade da REDH

Ensino, Pesquisa e Extensão são classicamente os três pilares da universidade pública brasileira. Entretanto, enquanto os dois primeiros são campos consagrados e bem consolidados, a Extensão continua objeto de controvérsias. Por vários anos a academia entendeu a Extensão apenas como uma forma de prestação de serviços à Sociedade, com enfoque ao caráter assistencialista da ação. Depois de muitos debates e experiências acumuladas, esse conceito está mudando. Hoje, Extensão é, principalmente, troca de saberes entre a Academia e a Sociedade. É, portanto, um processo de aprendizagem mútua.

As transformações ocorridas na gestão da Extensão exigem agora da Universidade a instalação de dinâmicas de acompanhamento $e$ avaliação das suas ações, a partir de um processo permanente de registro e controle pelas unidades acadêmicas e de uma nova lógica de significação das ações baseada na vinculação orgânica da extensão às atividades de ensino, posto que a UFPA coloca como desafio até 2009 institucionalizá-la por meio dos projetos pedagógicos dos cursos de graduação, em atendimento à Meta 23 do Plano Nacional de Educação em cumprimento ao seu novo Regulamento da Graduação. Tais marcos têm desafiado a UFPA, seus docentes, discentes e técnicos, no sentido de institucionalizar a vivência de ações extensionistas enquanto síntese do fazer universitário $e$ a realidade social, questionando o seu papel e redimensionando-o rumo à uma atuação mais eficaz na sociedade.

Por outro lado, é essencial compreender que a dimensão inclusiva da extensão, mani- 
festa na consolidação das políticas de assistência estudantil, ainda são um desafio cuja superação apresenta naturezas diversas (de proteção, de diversidade, de sensibilidade e de inovação), afinal, seu fortalecimento como dimensão estratégica representa, sem dúvida, uma real contribuição para a retomada da democracia $e$ da cidadania em nosso país.

A experiência aqui apresentada pretende atender um total de 500 (quinhentas) pessoas e agrega na perspectiva extensionista uma prática acadêmica na qual estudantes da Universidade Federal do Pará, dos cursos de Ciências da Computação, Comunicação, Enfermagem, Farmácia, Medicina, Nutrição, Odontologia, Pedagogia e Serviço Social atuam de forma direta e indireta junto às populações, oportunizando o aprendizado e a prática dos Direitos Humanos, estimulando a criticidade $e$, por sua vez, motivando-as a reivindicar seus direitos junto às autoridades, observando que a participação popular nas políticas públicas é fundamental para o monitoramento e compreensão dos direitos dos cidadãos como um todo. Revela-se, portanto, para além do ensino e da pesquisa, ação extensionista no mais puro sentido de serviço à sociedade, à sua emancipação $e$ desenvolvimento humano e, porque educativa, de maneira sustentável.

\section{REFERENCIAS}

GOMIDE, Denise (org.). Governo e Sociedade Civil: um debate sobre espaços públicos democráticos. São Paulo: ABONG, 2003.

GONH, Maria da Glória. Movimentos Sociais no Início do Século XXI: antigos e novos atores sociais. Petrópolis: Vozes, 2003.

UFPA. Pró-Reitoria de Extensão. Anteprojeto da Política de Assistência Estudantil/UFPA/Belém/Dezembro de 2007.

UFPA. Centro de Educação. Relatório da pesquisa sobre a questão racial na UFPA. Belém, UFPA, Novembro de 2004.

UFPA. Instituto de Ciências da Educação. Projeto Multicampisocial/UFPA/Belém/Dezembro de 2008.

UFPB. Pró-Reitoria de Extensão. Projeto de capacitação em Direitos Humanos. Disponivel em: <http://www.redh. brasil.net/oprojeto_restrito.php>. Acesso em: 05/2/2009.

Texto recebido em 16 de janeiro de 2009.

Texto aprovado em 19 de junho de 2009. 